\title{
Experience with Open Prostatectomy in Lomé, Togo
}

\author{
Tchilabalo M. Kpatcha1 ${ }^{*}$, Boyodi Tchangai'2, Kodjo Tengue ${ }^{1}$, Fousséni Alassani², \\ Tsipa Anoukoum1, Komlan Gnassingbe ${ }^{4}$ \\ ${ }^{1}$ Department of Urology, the University Teaching Hospital of Lomé, Togo
${ }^{2}$ Departement of Surgery, the University Teaching Hospital of Lomé, Togo
${ }^{3}$ Department of Pathology, the University Teaching Hospital of Lomé, Togo
${ }^{4}$ Department of Pediatric Surgery, the University Teaching Hospital of Lomé, Togo
Email: "fakpatcha@yahoo.fr
} Gnimdou Botcho', Tchin Darre ${ }^{3}$, Essomindedou Leloua', Komi H. Sikpa', Edoe V. Sewa ${ }^{1}$,

Received 29 March 2016; accepted 8 May 2016; published 11 May 2016

Copyright (C) 2016 by authors and Scientific Research Publishing Inc.

This work is licensed under the Creative Commons Attribution International License (CC BY).

http://creativecommons.org/licenses/by/4.0/

(c) (i) Open Access

\begin{abstract}
Background: Open prostatectomy is the most commonly available surgical procedure for benign prostatic hyperplasia and this is the case in most countries in West African even with all the limitations of the procedure. Objective: The objective is to determine the pattern and outcomes of open prostatectomy in Lomé. Patients \& Methods: From December 2011 to November 2012, we conducted a descriptive cross-sectional study on a series of patients treated for prostate adenoma. Dysuria was assessed using the International Prostate Symptom Score (IPSS). The history of each patient was recorded, as well as paraclinical data. All patients were surgically treated via abdominal incision procedure. The data obtained included the patients' demographics, clinical features, the IPSS scores, investigations, type of open prostatectomy, outcome and follow-up. The data were analyzed for means and frequencies using Epi Info version 3.5.3. Results: Fifty-four consecutive patients underwent surgery consecutively, their ages ranging from 40 to 92 years, with an average of $67.27 \pm 12.50$ years. In all, $46(85.2 \%)$ patients presented with obstructive symptoms and $26(48.1 \%)$ presented with urinary retention. The average prostate volume was $114.31 \pm$ $20.11 \mathrm{~cm}^{3}$ with a range of $31-485 \mathrm{~cm}^{3}$. The average blood loss at surgery was $425.92 \pm 38.2 \mathrm{ml}$ with an average operating time of $66.05 \pm 15.75$ mins and the main complications were hemorrhaging and clot retention in $7(13 \%)$, epididymo-orchitis in $9(16.7 \%)$, and urinary incontinence in $6(11.1 \%)$ patients. IPSS scores were under 7 in $92 \%$ of patients three months after surgery and the mortality rate was $3.7 \%$. Conclusion: This study has shown that open prostatectomy in our environment is still the commonest surgical option for benign prostatic hyperplasia with good outcomes though with manageable complications.
\end{abstract}

"Corresponding author.

How to cite this paper: Kpatcha, T.M., Tchangai, B., Tengue, K., Alassani, F., Botcho, G., Darre, T., Leloua, E., Sikpa, K.H., Sewa, E.V., Anoukoum, T. and Gnassingbe, K. (2016) Experience with Open Prostatectomy in Lomé, Togo. Open Journal of Urology, 6, 73-79. http://dx.doi.org/10.4236/oju.2016.65014 
Keywords

Open Prostatectomy, Benign Prostate Hyperplasia, Good Outcome, Complications, Lomé, Togo

\section{Introduction}

Open prostatectomy is still a common option in developing countries while less invasive procedures with optimal outcomes are practiced in industrialized countries [1] [2]. Endoscopy undoubtedly represents the major innovation in surgical treatment of benign prostatic hyperplasia, notably through endoscopic resection, TUNA (Transurethral Needle Ablation), HIFU (High Intensity Focused Ultrawave) and VLAP (Visual laser Ablation of the Prostate). These new procedures have allowed for dramatically reduced morbidity, mortality and perioperative mortality rates, minimizing blood loss, postoperative pain and hospital stay [3] [4]. Open prostatectomy however still remains important despite the emergence of these many minimally invasive techniques. It is the technique that allows the most anatomical extraction of adenomatous tissue and the one that guarantees lasting functional results with negligible risk of repeated surgery after five years [5] [6]. The procedure is however burdened by significant complications such as hemorrhaging, surgical site infection, or even decubitus complications [7].

At the Sylvanus Olympio University Hospital Center, endoscopic methods are still in their infancy; prostatectomy via abdominal incision remains the surgical method of choice for treatment of benign prostatic hyperplasia. The aim of this study was to determine the pattern, morbidity and mortality rates and outcomes of open prostatectomy at the Sylvanus Olympio University Hospital Center in Lomé, Togo over a period of one year.

\section{Patients \& Methods}

We conducted a retrospective and descriptive study of all patients undergoing open prostatectomy at Sylvanus Olympio University Hospital Centre, Lome, Togo between December 2011 and November 2012. The cases of our study were enrolled among patients treated in the urology department for benign prostatic hyperplasia (BPH). Inclusion criteria were the formal diagnosis of BPH and indication of prostatectomy. The sample size corresponded to an open prostate surgery activity conducted in a year in urology department. Each patient underwent a complete urological examination with digital rectal exam to assess the size and characteristics of the prostate after determining the international prostate symptom score (IPSS) followed by abdominal ultrasonography with emphasis on the kidney, ureter, bladder and prostate. Prostate specific antigen (PSA) levels were measured in the patients. Patients with high PSA greater than $10 \mathrm{ng} / \mathrm{ml}$ had their prostate biopsied transrectally to rule out carcinoma of the prostate. All those with histological evidence of carcinoma of the prostate were excluded from the study.

All the patients included in this study underwent preoperative evaluation testing including prothrombin time (PT), urea, electrolytes and creatinine, fasting blood glucose, full blood count, blood grouping, chest radiography and electrocardiography.

Open prostatectomy was performed on the patients under spinal anesthesia via a suprapubic subumbilical incision; the choice of the approach used was linked to the surgeon's habit. The patients' demographic and clinical data as well as the duration of surgery, blood loss and outcome were recorded in a proforma and analyzed for means and frequencies using Epi Info version 3.5.3. Postoperative patients were monitored on a daily basis up until hospital discharge and then once monthly for three months; the surgical specimens of the prostate were subjected to histopathological examination. Parameters studied during postoperative monitoring were: the quality of micturition as evaluated by the IPSS score, hemoglobin levels and post-operative complications.

\section{Results}

Fifty-four patients were included in the study. Their average age was $67.27 \pm 12.50$ years with a range of 40 - 92 years. The most represented age group was 60 to 69 years in 23 (42.6\%) patients; one patient was under 50 years of age as shown in Figure 1 while 18 (39\%) had hypertension and 2 (3.7\%) had diabetes mellitus. Also 13 (24\%) patients had had inguinal herniorrhaphy for hernias that occurred after the symptoms of prostatectomy began. 


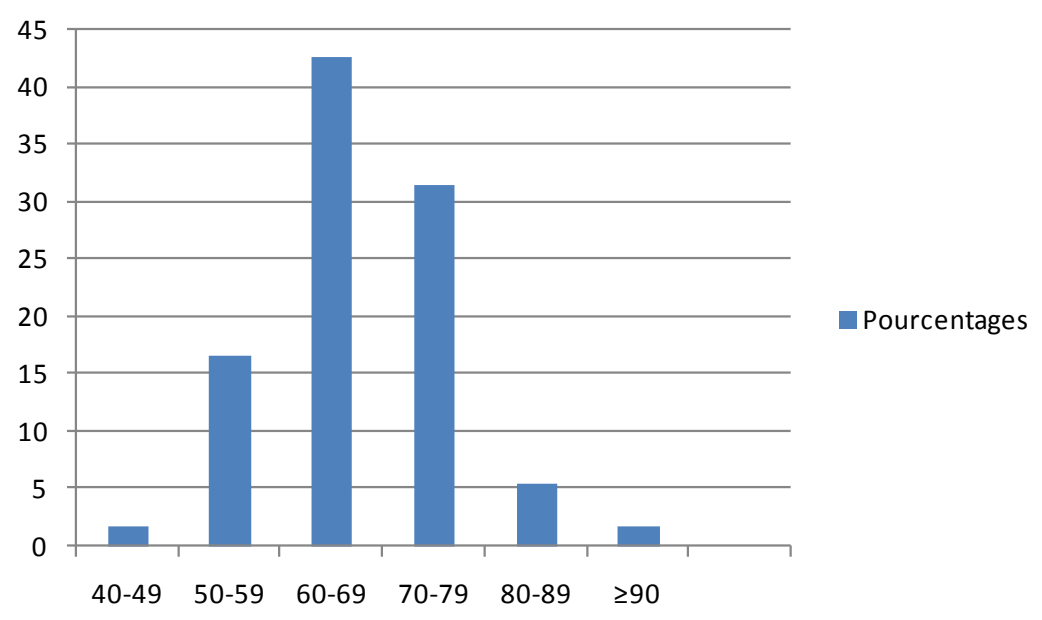

Figure 1. Age distribution of the patients.

In all, 46 (85.2\%) patients had severe dysuria with IPSS scores $>20$ and 26 (48.1\%) patients had urinary retention. Prostate-specific antigen (PSA) measured in 43 patients had an average level of $20.33 \mathrm{ng} / \mathrm{ml}$. This value was higher than normal $(4 \mathrm{ng} / \mathrm{ml})$ in $81 \%$ of patients. In eleven patients, the PSA could not be determine because of the lack of financial resources. The open prostatectomy was transvesically in 53 (98.1\%) patients and retropubically in 1(1.8\%) patient. Other patient characteristics are shown in Table 1.

The post-operative complications included haemorrhage in 7 (13\%) patients, epididymorchitis in 9 (16.7\%), surgical site infection in 6 (11.1\%), urinary incontinence in 6 (11.1\%) and in the long run, 3 (5.6\%) had recurrent mild dysurea. The follow-up of all the patients was three months and the prognosis was assessed on the micturition quality. The average hospital stay was $9.4 \pm 3.5$ days with a range of $7-30$ days while $92 \%$ of the patient had an IPSS score below 7 as shown in Table 2.

The histological test of pieces of prostatectomy showed in all cases an adenomyofibroma associate with a chronic prostatitis .We recorded 2 (3.7\%) deaths in this study; 1 (1.8\%) patient died of myocardial infarction four weeks after surgery and the other died of hepatic encephalopathy.

\section{Discussion}

\subsection{Sociodemographic Aspects}

The average age of our patients (67.27) is comparable to that reported in the literature regarding studies of open surgery for prostatic adenoma [8] [9]. This is the prostate pathology typically diagnosed in elderly patients above 50 years of age. Increased life expectancy in all regions of the world entails aging of the general population and thus more subjects with benign prostatic hypertrophy. The main comorbidity found in our series is hypertension, with 33\% prevalence. This relatively high rate reflects the increasing incidence of cardiovascular disease in the Togolese population. A patient was exceptionally under fifty years in our series; the prostatic hypertrophy is rare before fifty years. The metabolic syndrome has been incriminated in the physiopathology of the increase in the prostatic gland volume in young patient, and mainly with diabetes and obesity [10]. But in our case, the patient was neither diabetic nor obese.

Inguinal hernia was the predominant surgical pathology in our subjects' history. It is secondary for dysuric patients suffering from intra-abdominal hypertension caused by pushing efforts during micturition. In our regions, manual activities in populations constitute an aggravating risk factor for incidence of inguinal hernia.

\subsection{Clinical Aspects}

Acute urinary retention constituted the most frequent indication for surgery in our series; this mechanical complication of prostatic adenoma is frequently the reason for the choice of surgical treatment in Sub-Saharan Africa, with frequencies ranging from $34.7 \%$ in Mali [11], to $77.85 \%$ in Benin [12]. This heightened frequency of acute urinary retention is associated with delayed medical consultations for micturition disorders, allowing time for the adenoma to achieve sizeable volumes. Added to this is the poor observance of pharmaceutical treatments, 
Table 1. Characteristics of the patients.

\begin{tabular}{ccc}
\hline Characteristics & Average & Extremes \\
\hline Age (years) & $67.27 \pm 12.50$ & $40-92$ \\
IPSS & 25.68 & $12-35$ \\
PSA (ng/ml) & 20.33 & $0.7-26.40$ \\
Prostate volume (cm $\mathbf{c m}^{\mathbf{3}}$ & $114.31 \pm 20.11$ & $31-485$ \\
Duration of intervention (min) & $66.05 \pm 11.75$ & $50-120$ \\
Blood loss (ml) & $425.92 \pm 38.20$ & $100-800$ \\
\hline
\end{tabular}

Table 2. Post-operative outcomes of the patients.

\begin{tabular}{ccccc}
\hline & Preoperative & M1 post op & M2 post op & M3 post op \\
\hline \multirow{2}{*}{ Average IPSS } & 25.68 & 8 & 5.57 & 4.57 \\
\multirow{2}{*}{ Postoperative complications } & Infections (\%) & 25.9 & - & - \\
& Urinary incontinence (\%) & - & - & 5.6 \\
& Obstructive symptoms (\%) & - & - & - \\
\hline
\end{tabular}

M1 post op: first month after prostatectomy; M2 post op: second month after prostatectomy; M3 post op: third month after prostatectomy.

principally due to economic reasons. The major current indication for prostatic adenomectomy via abdominal incision is a prostate volume greater than $60 \mathrm{ml}$ [13]. The surgical treatments of reference are transurethral resection of the prostate (TURP), cervico-prostatic incision and prostatic adenomectomy. Cervico-prostatic incision is valuable mostly in younger patients or those wishing to retain ejaculation; this technique is only feasible in cases of prostate volume lower than $30 \mathrm{ml}$ and in the absence of a median lobe [13].

\subsection{Paraclinical Aspects}

Prostate-specific antigen (PSA) was above normal reference levels in $81 \%$ of the patients in our series. PSA level varies greatly according to prostate size and presence or absence of tissue inflammation. Large gland size and urinary tract infection are factors that increase PSA levels. These points explain the very high levels in our patients who had large prostate volumes; furthermore, dosages of this antigen were not made within the timeframe needed to avoid a skewed result, as any endo-urethral maneuver leads to an increase in total PSA.

Average prostate gland volume determined by suprapubic ultrasound in our patients was $114.31 \mathrm{~cm}^{3}$; this value is consistent with the results of previous studies, in particular Fall's study, which reported an average volume of $95 \mathrm{~cm}^{3}$ [14]. The best surgical technique ensuring complete removal of these large adenomas in our patients is therefore adenomectomy performed by abdominal incision.

\subsection{Therapeutic Aspects}

The transvesical prostatic adenomectomy technique was the most used in our series as being the best mastered. It provides a better view of the adenoma, allows easier ablation of the median lobe, and guarantees avoidance of the ureteral meatuses during hemostasis of the prostatic cavity. It is also a rapid procedure when mastered. The duration of surgery was generally one hour; simultaneous treatment of inguinal hernia in three patients extended this duration. Fall [14] in a study in which 2/3 of the surgeons had over 4 years experience, reported an operating time of less than one hour in $63 \%$ of cases.

\subsection{Evolutionary Aspects}

The major early complication in our study was hemorrhaging from the prostatic cavity following adenomecto- 
my. Contributing factors are preoperative prostate infection, a large prostate volume and a long operating time. In Reich's series the rate of hemorrhaging was $2.9 \%$ [15], substantially lower than in ours. In our study, hemorrhaging occurred in $14 \%$ of cases; the large volumes of adenomas and hypertension in our patients have surely been negative factors. This calls for controls and a lowering of blood pressure levels by the anesthetist during surgery with a high risk of hemorrhaging, especially during prostatic adenomectomy. The high rate of blood transfusions in our study contrasts with results in the literature; $8.6 \%$ of patients on average received blood transfusions in a review of 29 studies conducted between 1986 and 1988 [7]. The 44\% observed in our study are related to the fact that our patients were preoperatively anemic, explaining prophylactic blood transfusion in a large majority of cases.

Open prostatectomy can lead to a significant bleeding. Elshal [16] reported up to $24.5 \%$ blood transfusion in 163 operated patients following a peroperative bleeding. According to some authors, the risk of bleeding remains the same whether the prostate surgery is carried out through transvesical approach or retropubic one [17] [18]. But this conclusion is not shared by everyone; in fact, a study carried out on 240 operated patients through retropubic tract (i.e., following Millin’s technic). Brian et al. concluded that Millin's technic permitted to limit peroperative bleeding as opposed to that of transvesical [19]. According to the author, this difference is due to the fact that retropubic approach of the prostate could permit a more efficient hemostasis. We think that the choice of either technic must take into account the habit of the surgeon. Hence, the best technic could be the one that the surgeon masters better.

Epididymo-orchitis was the most common infectious complication observed in $16.7 \%$ of patients. This rate is considerably higher than that found by Fall [14] estimated at 5\% and 3.4\% by Fourcade [20]. This high rate of infectious complications in our study raises the problem of aseptic conditions which seem lax in our context even though only $11.1 \%$ of operated patients had an infection of the wound as opposed to $19 \%$ in Fall's series [14]. A prolonged urinary catheterization constitute favorable factor for urinary infections in which vesical catheter represents an entry for germs. A cytobacteriological test of urine would be useful before prostatectomy in order to treat any urinary infection before surgery. Lack of this precaution in our study has surely contributed to the rise in the rate of inflectional complications after surgery.

Approximately $17 \%$ of our patients still had complications three months after surgery; the main complication was urinary incontinence, observed in six patients. The rate of urinary incontinence following prostatic adenomectomy varies in the literature and its definition is still a problem, particularly in relation to the time after which it may be considered a definitive complication of prostate surgery. In his series, Doll had a 38\% incidence of urinary leakage during the first postoperative trimester with a gradual reduction of this percentage during the first year [21]. Mearini had only listed a 1\% incidence [22]. Enucleation seems to be the determining factor in this complication; a traumatic maneuver can damage the striated sphincter located just below the prostatic urethra. Therapeutically, anticholinergics used for at least one month can improve symptoms; otherwise an artificial sphincter is a last resort.

Hospital stay was longer in cases where one or more complications had occurred, but it was globally comparable to the literature: 10 days for Fall [14] and 12.1 days for Fourcade [20]. Functional results of prostatic adenomectomy were favorable for our patients as IPSS scores show. The IPSS average effectively fell from 25.68 before surgery to 4.57 in the third month of postoperative observation. This marked improvement confirms that despite the advent of endoscopic methods, open surgery retains its value, especially in our regions where adenomas often have large volumes.

Prostatic adenomectomy-related perioperative mortality has decreased over the last thirty years to roughly $0.25 \%$ in contemporary series [7]. The mortality rate was equal to $3.7 \%$ in our study, which is comparable to Fourcade [20] who reported a rate of $5 \%$, as well as Vagner, who reported a mortality rate of $3.2 \%$ [23]. It should be noted that the mortality rate in prostatic adenomectomy appears to be primarily related to the patient's condition, notably comorbidities due to old-age conditions such as hypertension, diabetes and heart disease. Of the two patients who died during the study, one suffered from cardiovascular disease and the other from hepatic encephalopathy. We believe that these deaths were caused by an aggravation of preexisting conditions. This should incite greater rigor in preoperative assessment, as well as in postoperative monitoring of patients at risk.

Undoubtedly, our study concerns a limited number of cases but it has the merit to take stock of the therapeutic and progressive aspects of one of the most practical operations performed in our hospital. The weakness of our study resides in its limited aspect regarding trans-urinary catheterization, and this has not facilitated its comparison with most contemporary studies. 


\section{Conclusion}

This study has shown that open prostatectomy in our environment is still the commonest surgical option for benign prostatic hyperplasia with good outcomes though with manageable complications.

\section{References}

[1] Suardi, N., Gallina, A., Salonia, A., Briganti, A., Cestari, A., Guazzoni, G., Rigatti, P. and Montorsi, F. (2009) Open Prostatectomy and the Evolution of HoLEP in the Management of Benign Prostatic Hyperplasia. Minerva Urologica e Nefrologica, 61, 301-308.

[2] Ferretti, M. and Phillips, J. (2015) Prostatectomy for Benign Prostate Disease: Open, Laparoscopic Robotic Techniques. The Canadian Journal of Urology, 22, 60-66.

[3] Geavlet, B., Stanescu, F., Iacoboaie, C. and Geavlet, P. (2013) Bipolar Plasma Enucleation of the Prostate vs Open Prostatectomy in Large Benign Prostatic Hyperplasia Cases-Medium Term, Prospective, Randomized Comparison. BJU International, 111, 793-803. http://dx.doi.org/10.1111/j.1464-410X.2012.11730.x

[4] Parsons, J.K., Rangarajan, S.S., Palazzi, K. and Chang, D. (2015) A National, Comparative Analysis of Perioperative Outcomes of Open and Minimally Invasive Simple Prostatectomy. Journal of Endourology, 29, 919-924. http://dx.doi.org/10.1089/end.2014.0879

[5] Lourenco, T., Armstrong, N., N’Dow, J., Nabi, G., Deverill, M., Pickard, R., Vale, L., MacLennan, G., Fraser, C., McClinton, S., Wong, S., Coutts, A., Mowatt, G. and Grant, A. (2008) Systematic Review and Economic Modelling of Effectiveness and Cost Utility of Surgical Treatments for Men with Benign Prostatic Enlargement. Health Technology Assessment, 12, 1-146, 169-515. http://dx.doi.org/10.3310/hta12350

[6] Oelke, A.B., Descazeaud, A., Emberton, M., Gravas, S., Michel, M.C., N’Dow, J., Nordling, J. and de la Rosette, J.J. (2013) EAU Guidelines on the Treatment and Follow-Up of Non-Neurogenic Male Lower Urinary Tract Symptoms Including Benign Prostatic Obstruction. European Urology, 64, 118-140. http://dx.doi.org/10.1016/j.eururo.2013.03.004

[7] Madersbacher, S., Lackner, J., Brossner, C., Rohlich, M., Stancik, I., Willinger, M. and Schatzl, G. (2005) Prostate Study Group of the Austrian Society of Urology Reoperation. Myocardial Infarction and Mortality after Transurethral and Open Prostatectomy: A Nation-Wide, Long Term Analysis of 23,123 Cases. European Urology, 47, 499-504. http://dx.doi.org/10.1016/j.eururo.2004.12.010

[8] McNeill, S.A., Hargreave, T.B. and Roehrborn, C.G.; Alfaur Study Group (2005) Alfuzosin 10 mg Once Daily in the Management of Acute Urinary Retention: Results of a Double-Blind Placebo-Controlled Study. Urology, 65, 83-89. http://dx.doi.org/10.1016/j.urology.2004.07.042

[9] Narayan, P. and Tewari, A. (1998) Overview of Alpha-Blocker Therapy for Benign Prostatic Hyperplasia. Urology, 51, 38-45. http://dx.doi.org/10.1016/S0090-4295(98)00054-5

[10] Yim, S.J., Cho, Y.S. and Joo, K.J. (2011) Relationship between Metabolic Syndrome and Prostate Volume in Korean Men under 50 Years of Age. Korean Journal of Urology, 52, 390-395. http://dx.doi.org/10.4111/kju.2011.52.6.390

[11] Traoré, C.B., Kamaté, B., Touré, M.L., Diarra, T. and Bayo, S. (2006) Aspects anatomopathologiques, cliniques et radiologiques des tumeurs bénignes de la prostate au Mali: A propos de 759 cas. Mali Médical, 21, 32-34.

[12] Hodonou, R., Yetchenou, J.J., Akpo, C., Aguemon, R. and Podonou, N. (1998) Aspects épidémiologiques, diagnostiques et thérapeutiques de l'adénome de la prostate au CNHU de Cotonou. A propos de 149 cas. Le Bénin Médical Spécial Urologie No. 9.

[13] Descazeaud, A., Robert, G., Delongchamps, N.B., Cornu, J.N., Saussine, C., Haillot, O., Devonec, M., Fourmarier, M., Ballereau, C., Lukacs, B., Dumonceau, O., Azzouzi, A.R. and de la Taille, A.; Comité des troubles mictionnels de l'homme de l'Association française d'urologie (2012) Bilan initial, suivi et traitement des troubles mictionnels en rapport avec hyperplasie bénigne de prostate: recommandations du CTMH de l'AFU. Progres en Urologie, 22, 977988. http://dx.doi.org/10.1016/j.purol.2012.10.001

[14] Fall, P.A., Gueye, S.M., Ndoye, A.K., Diao, B., Thiam, O.B.K., Abdallahi, M.O.C., Sylla, C., Ba, M. and Diagne, BA. (2002) Mortalité et morbidité précoces après adénomectomie prostatique par voie transvésicale. African Journal of Urology, 8, 20-23.

[15] Reich, O., Gratzke, C., Bachmann, A., Seitz, M., Schlenker, B., Hermanek, P., Lack, N. and Stief, C.G.; Urology Section of the Bavarian Working Group for Quality Assurance (2008) Morbidity, Mortality and Early Outcome of Transurethral Resection of the Prostate: A Prospective Multicenter Evaluation of 10,654 Patients. The Journal of Urology, 180, 246-249. http://dx.doi.org/10.1016/j.juro.2008.03.058

[16] Elshal, A.M., El-Nahas, A.R., Barakat, T.S., Elsaadany, M.M. and El-Hefnawy, A.S. (2013) Transvesical Open Prostatectomy for Benign Prostatic Hyperplasia in the Era of Minimally Invasive Surgery: Perioperative Outcomes of a 
Contemporary Series. Arab Journal of Urology, 11, 362-368. http://dx.doi.org/10.1016/j.aju.2013.06.003

[17] Autorino, R., Zargar, H., Mariano, M.B., Sanchez-Salas, R., Sotelo, R.J., Chlosta, P.L., Castillo, O., Matei, D.V., Celia, A., Koc, G., Vora, A., Aron, M., Parsons, J.K., Pini, G., Jensen, J.C., Sutherland, D., Cathelineau, X., Nuñez Bragayrac, L.A., Varkarakis, I.M., Amparore, D., Ferro, M., Gallo, G., Volpe, A., Vuruskan, H., Bandi, G., Hwang, J., Nething, J., Muruve, N., Chopra, S., Patel, N.D., Derweesh, I., Champ Weeks, D., Spier, R., Kowalczyk, K., Lynch, J., Harbin, A., Verghese, M., Samavedi, S., Molina, W.R., Dias, E., Ahallal, Y., Laydner, H., Cherullo, E., De Cobelli, O., Thiel, D.D., Lagerkvist, M., Haber, G.P., Kaouk, J., Kim, F.J., Lima, E., Patel, V., White, W., Mottrie, A. and Porpiglia, F. (2015) Perioperative Outcomes of Robotic and Laparoscopic Simple Prostatectomy: A European-American Multi- Institutional Analysis. European Urology, 68, 86-94. http://dx.doi.org/10.1016/j.eururo.2014.11.044

[18] Coelho, R.F., Chauhan, S., Sivaraman, A., Palmer, K.J., Orvieto, M.A., Rocco, B., Coughling, G. and Patel, V.R. (2012) Modified Technique of Robotic-Assisted Simple Prostatectomy: Advantages of a Vesico-Urethral Anastomosis. BJU International, 109, 426-433. http://dx.doi.org/10.1111/j.1464-410X.2011.010401.x

[19] Briant, P.E., Navarro, R., Matillon, X., Coste, A.C., Adam, E., Champetier, D., Perrin, P., Ruffion, A. and Devonec, M. (2014) L’adénomectomie selon Millin à l'heure de l'énucléation laser: Résultats d'une série de 240 cas. Progres en Urologie, 24, 379-389. http://dx.doi.org/10.1016/j.purol.2013.09.030

[20] Fourcade, R.O., Landon, Y. and Teillac, P. (1993) Les résultats du traitement chirurgical de l’hypertrophie bénigne de la prostate. Rapport du 87ème Congrès de l'Association Française d’Urologie. Progres en Urologie, 3, 823-906.

[21] Doll, H., Black, N.A., McPherson, K., Flood, A.B., Williams, G.B. and Smith, J.C. (1992) Mortality, Morbidity and Complications Following Transurethral Resection of the Prostate for BPH. The Journal of Urology, 147, 1566-1573.

[22] Mearini, E., Marzi, M., Mearini, L., Zucchi, A. and Porena, M. (1998) Open Prostatectomy in Benign Prostatic Hyperplasia: 10-Year Experience in Italy. European Urology, 34, 480-485. http://dx.doi.org/10.1159/000019787

[23] Vagner, E.A., Goriunov, V.G. and Davidov, M.I. (1998) The Results of Prostatic Adenomectomy in Patients with Severe Concomitant Diseases. Khirurgiia (Mosk), 8, 40-44. 